\title{
ANOMALOUS AORTIC ORIGIN OF THE LEFT MAIN CORONARY ARTERY ASSOCIATED WITH ARTERIAL COMPRESSION - CASE REPORT
}

Davi Tenório ${ }^{1}$, Leonardo Miana ${ }^{1}$, Antonio Carlos de Almeida Barbosa Filho ${ }^{2}$, Monica ${\text { Gonzales } \text { Coronel }^{3} \text {, Gustavo Guerreiro }}^{1}$, Valdano Manuel ${ }^{4}$, Marcelo Jatene ${ }^{1}$, and fabio Jatene $^{5}$

${ }^{1}$ Heart Institute (InCor), Hospital das Clínicas da Faculdade de Medicina da Universidade de São Paulo

${ }^{2}$ Centro Universitário CESMAC

${ }^{3}$ Universidade de São Paulo Instituto do Coração

${ }^{4}$ Clínica Girassol

${ }^{5}$ Instituto do Coração, Hospital das Clinicas da Faculdade de Medicina da Universidade de Sao Paulo

December 29, 2020

\begin{abstract}
Anomalous Aortic Origin of Coronary Artery (AAOCA) is a rare finding, with varied presentation and symptomatology. Increasingly recognized by cardiac imaging, when found it raises questions about the appropriate approach and management. We present a case of an 11-year-old female who presented with episodes of shortness of breath, angina and syncope during exercise. Further investigation demonstrated episodes of nonsustained ventricular tachycardia on Holter and coronary angiotomography revealed that the left coronary artery had an anomalous origin from the right cusp with initial short intramural segment and significant external compression in its initial course between the aorta and the pulmonary artery. Patient was submitted to surgical correction with dissection of left coronary artery posterior to the pulmonary artery, coronary arteriotomy, roof ampliation with autologous pericardium and creation of neo-ostium in aorta. Patient had satisfactory postoperative recovery, was discharged on the fifth day post op, and remains asymptomatic after six months follow-up. Herein we present surgical video and postoperative echo and CT scan.
\end{abstract}

\section{Hosted file}

ANOMALOUS AORTIC ORIGIN OF THE LEFT MAIN CORONARY ARTERY WITH ARTERIAL COMPRESSION IN CHILD - CASE REPO available at https://authorea.com/users/386021/articles/501273-anomalous-aortic-origin-ofthe-left-main-coronary-artery-associated-with-arterial-compression-case-report

\section{Hosted file}

AAOC Light.mp4 available at https://authorea.com/users/386021/articles/501273-anomalousaortic-origin-of-the-left-main-coronary-artery-associated-with-arterial-compressioncase-report 

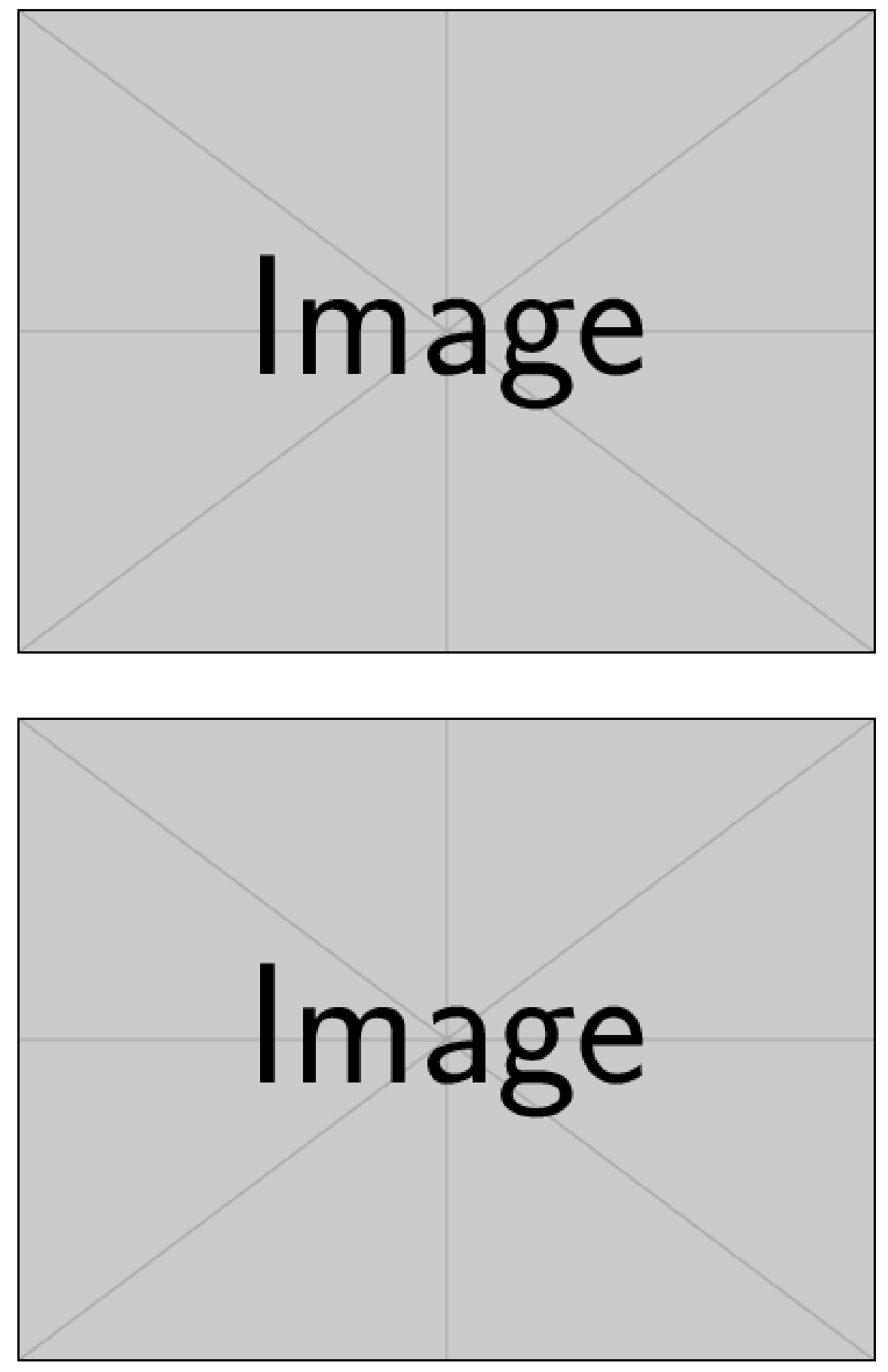

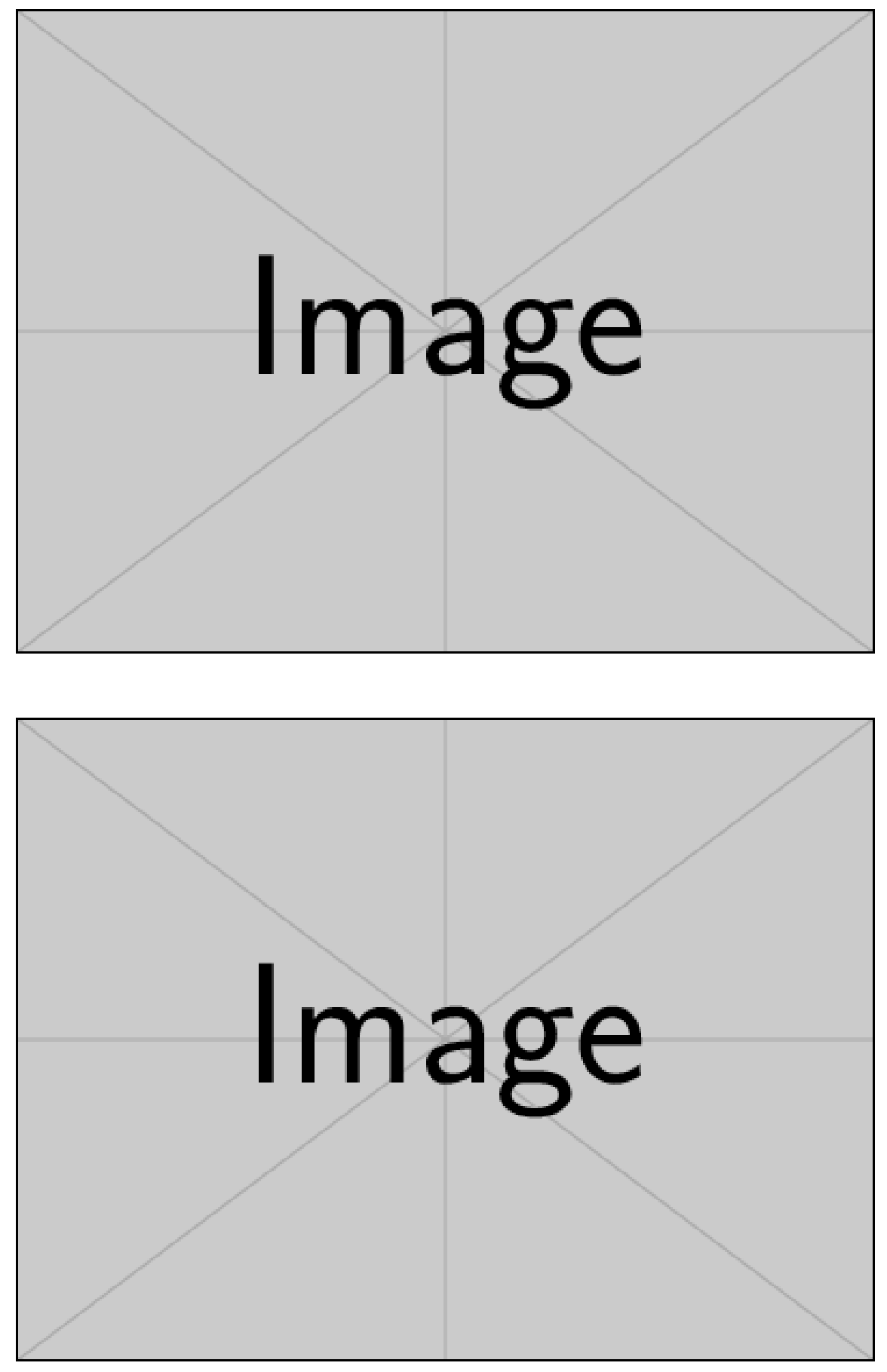

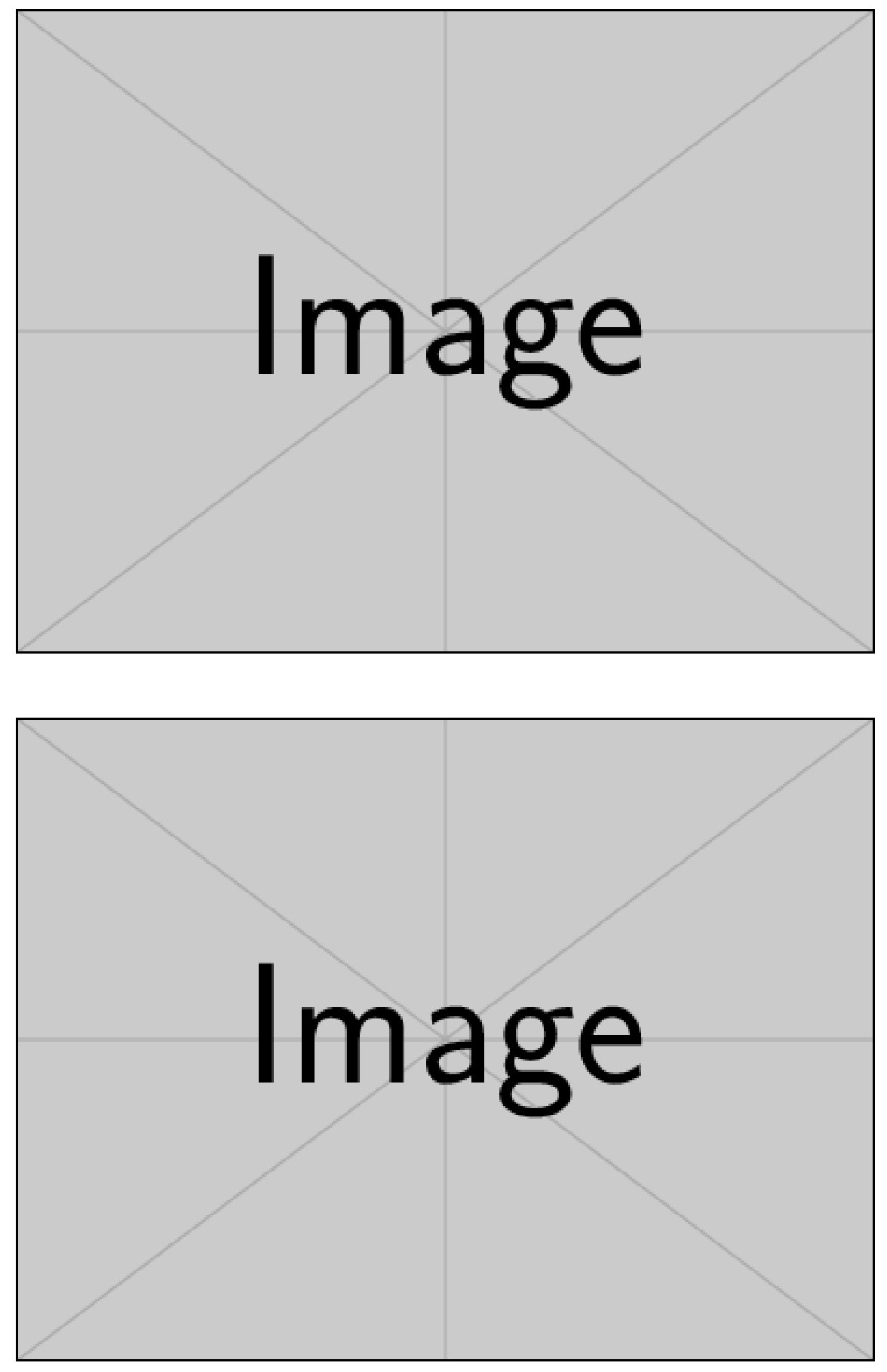